\title{
A DESCRIPTIVE NOTE ON THE GROWTH HABIT OF LOTUS PEDUNCULATUS CAV.
}

\author{
G. W. Sheath \\ Agronomy Deparfmenf, Massey University, \\ Palmerston $\mathrm{N}$ orth
}

A bstract

Morphological observations and measurements are presented on the growth habit of Lotus pedunculatus Cav. Establishing plants are characterized by a limited shoot-forming potential, particularly in association with weak crown activity. Plant resilience is improved with rhizome development by providing regrowth sites, carbohydrate storage and a colonizing potential. In the established plant, underground organs are the dominant plant components and their expansion patterns are discussed. Aerial growth is initiated as crown shoots, axillary shoots and basal shoots arising from rhizomatous material,

\section{INTRODUCTION}

THE RECENT RELEASE of the tetraploid Lotus pedunculafus Cav. 'Grasslands Maku' (Armstrong, 1974) has highlighted the need for knowledge on the agronomic traits of $L$. pedunculafus and possible management practices. Further interest has also been prompted by recent research findings proclaiming its non-bloating properties (Jones et al., 1970), grass grub resistance (Farrell and Sweeney, 1974; Kain and Atkinson, 1975; Sutherland, 1975) and low phosphate requirements (Brock, 1973). However, an appreciation of the growth habit of $\mathrm{L}$. pedunculatus is necessary if research into and extension of this pasture legume is to be successful. The objective of this paper is to present for $L$. pedunculatus, some morphological observations and measurements, made principally in the southern North Island region on the cultivar 'Grasslands Maku'.

\section{ESTABLISHING PLANT}

The developing crown of an establishing $L$. pedunculatus seedling is weak. Depending on growing conditions, only one to six shoots will generally develop. For example, with autumn sowings, seedlings developing during subsequent cooler conditions will have fewer ( 2 to 3 per crown), although slightly more 
prostrate, aerial shoots than those sown in spring (4 to 5 per crown) and developing under warmer conditions. Establishing plants grown under increasing competition will also have fewer shoots, the extreme example occurring under dense cover crop conditions when only one tall, spindly shoot per crown is produced.

Removal of shoot apices does little to stimulate crown shoot development, and subsequent regrowth, if any, is primarily confined to axillary shoots on residual aerial growth.

The first initiation of underground rhizomes from the crown of a young plant generally occurs in late summer to mid-autumn. This is four to six months after spring sowings and can be up to one year after autumn sowings. With the development of this rhizomatous growth, plant resilience to defoliation and competition is greatly improved as these basal stems provide sites for regrowth and storage of carbohydrate reserves and enable the outward spread of the plant from the central primary crown and taproot.

\section{ESTABLISHED PLANT}

\section{UNDERGROUND GROWTH}

The underground complement of $L$. pedunculatus consists of several components, namely: crown, taproot, lateral roots and

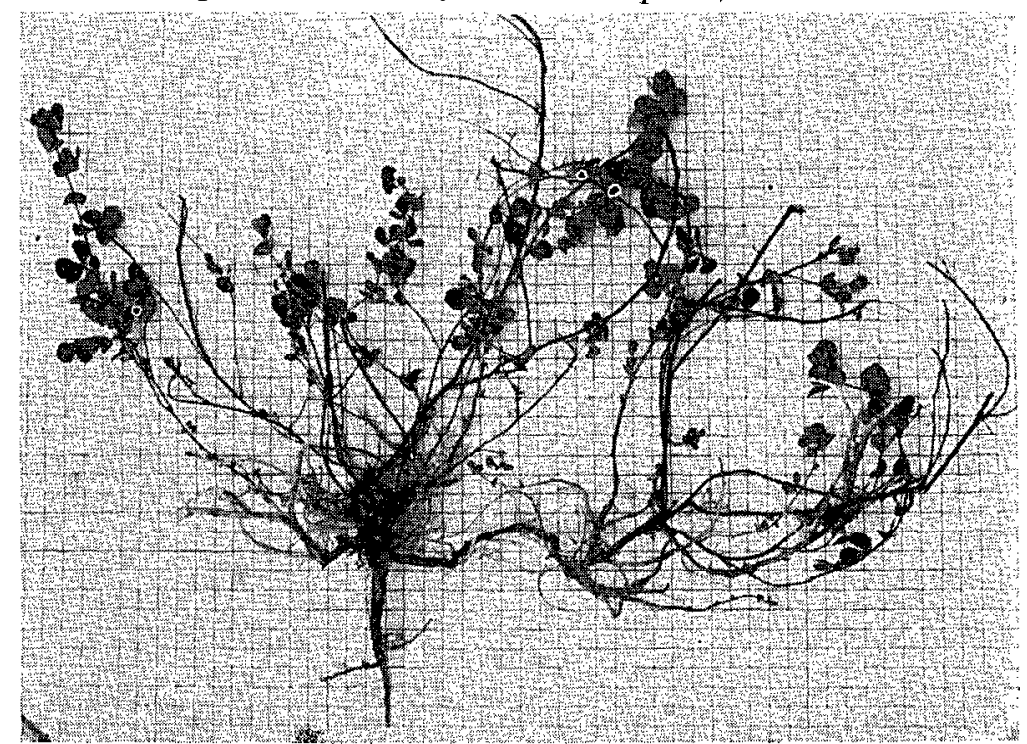

FIG. 1: An entire plant illustrating underground crown, taproot and rhizome growth plus aerial stubble and regrowth. (1.0 $\mathrm{cm}^{2}$ grid.) 
TABLE 1: COMPONENT DRY WEIGHT $\left(\mathrm{g} / \mathrm{m}^{2}\right)$ (Percentage of total plant weight in parentheses)

\begin{tabular}{lccccc}
\hline & \multicolumn{5}{c}{ Components } \\
\cline { 2 - 6 } $\begin{array}{l}\text { Cutting } \\
\text { Height }\end{array}$ & $\begin{array}{c}\text { Above } \\
\text { Ground }\end{array}$ & Rhizome & Crown + Taproot Adventitious \\
\cline { 3 - 6 } & & & & $109(28.5)$ & $17(4.5)$ \\
\hline $1.5 \mathrm{~cm}$ & $103(27.0)$ & $153(40.0)$ & $397(36.5)$ & $54(5.0)$ \\
$10.0 \mathrm{~cm}$ & $321(29.5)$ & $423(39.0)$ & & & \\
\hline
\end{tabular}

rhizomes pıus associated adventitious roots (Fig. 1). These organs combine to be a surprisingly large proportion of an established plant's total weight. Presented in Table 1 are plant component data taken during April, 1976, from a pure, 1\&year-old Maku stand which' was cut every three weeks to heights of 1.5 and $10.0 \mathrm{~cm}$.

Expansion of the rhizome system appears to be primarily restricted to the post-reproductive period of late summer/autumn, a period which also coincides with increasing starch accumulation. The extent of this expansion depends on how the plant is treated, being later and lower under more severe and/or frequent defoliations. However, reductions in rhizome bulk can occur during midspring to early summer. Selected sample dates illustrate this in Table 2 for the more severely defoliated Maku.

TABLE 2: RHIZOME DRY WEIGHT (mg/plant)

\begin{tabular}{lccccc}
\hline $\begin{array}{c}\text { Cutting } \\
\text { Height } \\
(\mathrm{cm})\end{array}$ & Oct. 21 & Dec. 2 & Janple Date 13 & Feb. 24 & Apr. 6 \\
\hline 1.5 & & & & 720 & 1040 \\
10.0 & 610 & 480 & 340 & 1300 & 2010 \\
\hline
\end{tabular}

The growth pattern of the crown/taproot complex is very similar to that of the rhizome system with weight increases and root extension being maximum over the late summer/autumn period. Again, restriction of aerial vegetative growth, through defoliation or competition, limits the expansion of these organs. In general, the taproot is the dominant rooting organ, being 10 to $15 \mathrm{~cm}$ in length for 1-year-old plants and increasing to 30 to $40 \mathrm{~cm}$ in older plants. However, "forked" root systems do exist with lateral roots, generally originating just below the crown, often being of a similar size and rooting depth to the primary taproot. 
Adventitious roots, plus associated nodules, can account for 3 to $5 \%$ of total plant weight. This mass of fine root is predominantly associated with rhizomes and thus tends to be superficially located in the soil horizon, rarely penetrating below $5 \mathrm{~cm}$. The bulk of adventitious roots is associated with new, rather than old rhizome material, and for this reason tends to be lower in spring and higher in autumn. Low soil moisture levels and severe and/or frequent defoliation also result in reduced adventitious rooting.

Accumulation of total non-structural carbohydrates (TNC) is centred on the crown, taproot and rhizome system. As with the absolute expansion of these organs, TNC increases over the autumn period, with maximum values of 25 to $30 \%$ being recorded for the Palmerston North environment in late autumn samples. Levels fall during winter and spring with minimum values in this locality ranging from 5 to $10 \%$ during the late spring to early summer period.

\section{A ERIAL Growth}

New aerial shoot growth in $L$. pedunculatus can develop from three separate regions, namely, the crown, the rhizomes and the leaf axils (Fig. 2).

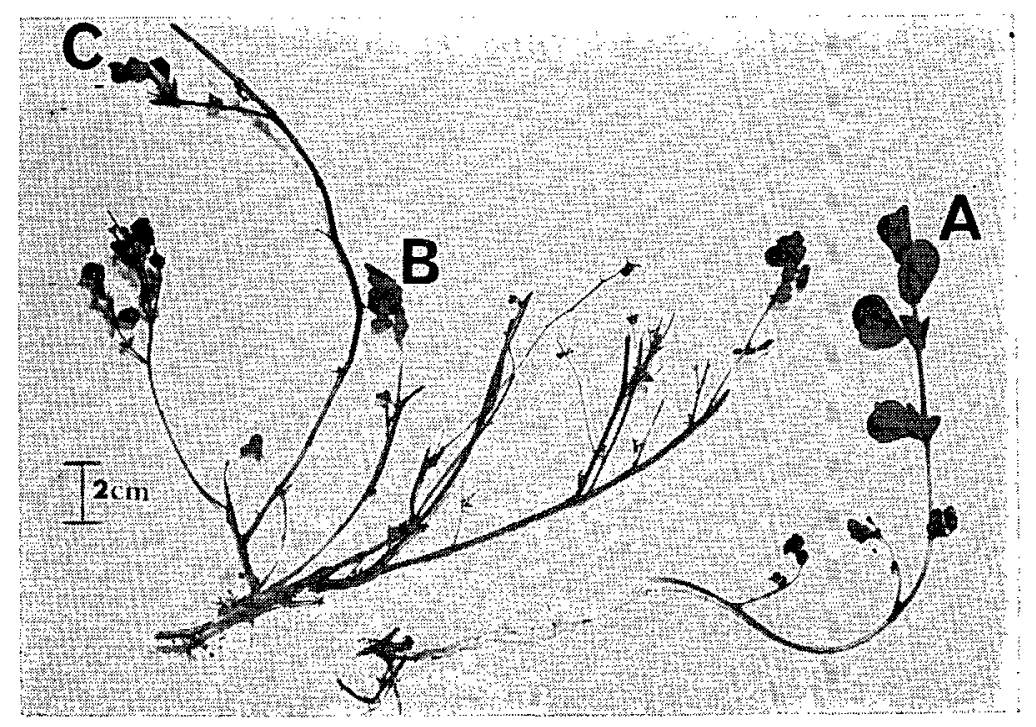

FIG. 2: Aerial shoot types: A-terminal rhizome shoot, B-lateral rhizome shoot, C-leaf axillary shoot. 


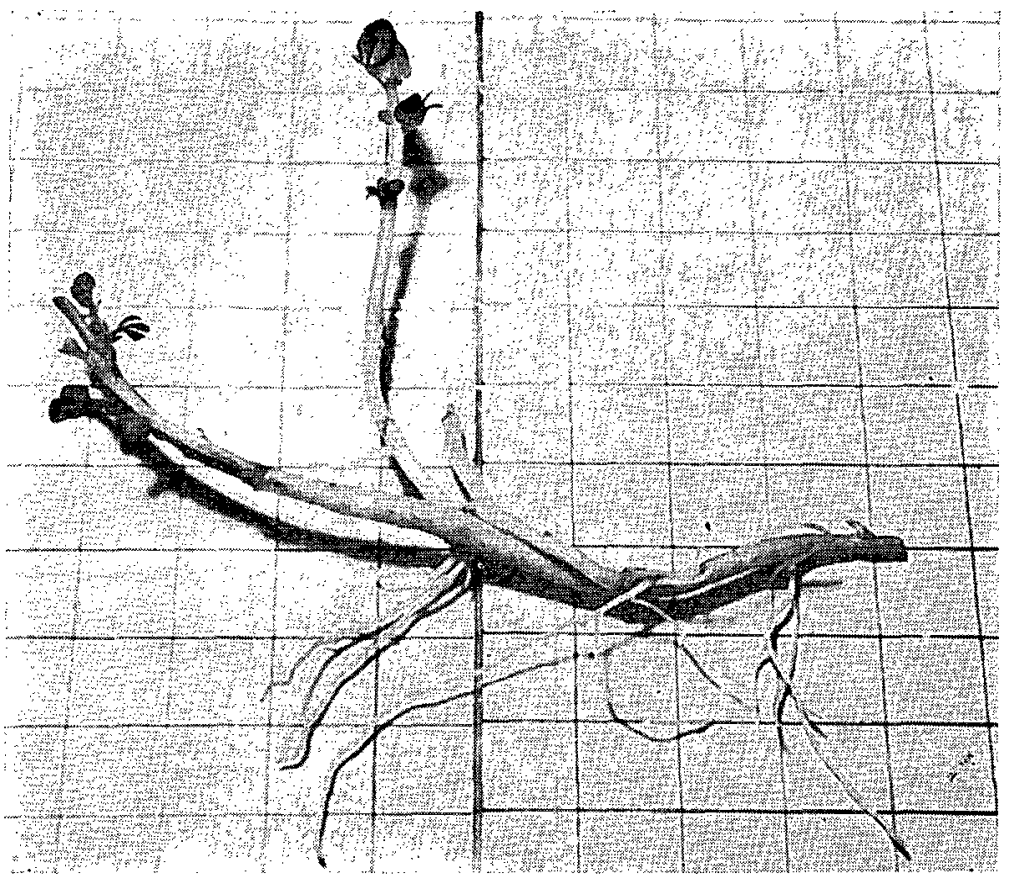

FIG. 3: Lateral rhizome shoots and associated scale-like leaves.

$$
\text { (1.0 } \mathrm{cm}^{2} \text { grid.) }
$$

Crown activity in L. pedunculatus is low and as an actual shootproducing crgan is insignificant compared with the rhizome system. Little, if any, crown shoot development occurs during spring/mid-summer. The most active period is that of late summer/ autumn, although only two to five shoots per plant are normally recorded. The majority of these shoots originate from the undersurface of the crown with very few arising from the upper surface.

Terminal rhizome shoots may themselves emerge above ground, become stoloniferous, particularly under cooler conditions, and/or then develop into upright aerial shoots. However, the bulk of aerial shoots of underground origin arise as lateral shoots from the nodes of more recent rhizomes or from enlarged nodes which may have developed on older rhizomes, 2 to $5 \mathrm{~cm}$ from the primary crown and taproot. As with rhizome expansion, potential shoot numbers of this basal origin are lowest in late spring/ mid-summer (4 to 15 per plant) rising to maximum values in autumn (25 to 40 per plant). 
While underground, rhizomes and associated lateral shoots have leaves that are reduced to stunted scale-like organs (Fig. 3) . Upon emergence from the soil normal leaves develop, although the initial ones are generally smaller in size.

As with shoots of underground origin, the growth of shoots arising in leaf axils is of a somewhat indeterminate nature. As the stem matures, axillary shoot development can occur with the terminal shoot apex still intact. For this situation bud release and shoot development are generally greatest in the middle region of the stem. Although two or three axillary buds may be released in a leaf axil, generally one will dominate and only one shoot will develop fully from a specific leaf axil.

Under defoliation, regrowth from axillary sites is greatest where the residual leaf component is most abundant and least senescent. Such responses would appear to be a reflection of varying shoot numbers.

\section{ACKNOWLEDGEMENTS}

I. M. Ritchie and Dr W. Kain from whose trials many of these observations were made.

\section{REFERENCES}

Armstrong, C. S., 1974. N.Z. Jl exp. Agric., 2: 333-6.

Brock, J. L. 1973. N.Z. /l agric. Res., 16: 483-91.

Farrell, J. A. K.; Sweeney, W. J., 1974. Ibid., 17: 69-72.

Jones, W. T.; Lyttelton, J. W.; Clarke, R. T. J., 1970. Ibid., 13: 149-56. Kain, W. M.; Atkinson, D. S., 1975. Proc. N.Z. Grassld Ass., 37: 132-7. Sutherland, 0. R. W., 1975. Ibid., 37: 126-31. 